\title{
Intradural Extra Medullary Cervical Anaplastic Ependymoma. Case Report and Review of the Literature
}

\author{
Daniel Memia Zolo1, Abd el Kader Moumouni1,2,3*, Anabi Daouda Diakhate1, \\ Dabou Abiba Tamoutabe ${ }^{4}$, Abderrahman Hamlat ${ }^{1}$ \\ ${ }^{1}$ Department of Neurosurgery, CHU Martinique, France \\ ${ }^{2}$ Department of Neurosurgery, CHU Kara, Togo \\ ${ }^{3}$ Department of Neurosurgery, CHU Sylvanus Olympio Lomé, Togo \\ ${ }^{4}$ Department of Radiology, HIA Parakou, Benin \\ Email: danielmemia@yahoo.fr, `makmas2003@gmail.com, anabida@yahoo.fr, moumouniabiba@gmail.com, \\ hamlat.adb@wanadoo.fr
}

How to cite this paper: Zolo, D.M., el Kader Moumouni, A., Diakhate, A.D., Tamoutabe, D.A. and Hamlat, A. (2018) Intradural Extra Medullary Cervical Anaplastic Ependymoma. Case Report and Review of the Literature. Open Journal of Modern Neurosurgery, 8, 414-423.

https://doi.org/10.4236/ojmn.2018.84037

Received: September 7, 2018

Accepted: October 27, 2018

Published: October 30, 2018

Copyright ( $) 2018$ by authors and Scientific Research Publishing Inc. This work is licensed under the Creative Commons Attribution International License (CC BY 4.0).

http://creativecommons.org/licenses/by/4.0/

\begin{abstract}
Introduction: Intra-dural and extramedullary ependymomas are rare lesions. We report a clinical case confirmed by the histology supported by the neurosurgery department of Martinique University Hospital. Clinical, paraclinical and therapeutic data will be compared to a literature review. Observation: A 38-year-old patient was admitted for tetraparesthesia evolving since 3 months, associated with a left hemiparesis. The clinical examination revealed deterioration of the general condition and a tetrapyramidal syndrome. MRI of the cervical spine revealed extensive cervical extra-medullary intradural lesion of $\mathrm{C} 3$ to $\mathrm{C} 5$. The treatment had been an excisional surgery that had been subtotal in two stages, supplemented by craniospinal radiotherapy because the pathological examination had found a grade III anaplasic ependymoma. Conclusion: Because of their rarity, the treatment of these forms of ependymoma is not yet well codified.
\end{abstract}

\section{Keywords}

Intradural Extramedullary Anaplasic Ependymoma, Surgery, Radiotherapy

\section{Introduction}

Spinal ependymomas are glial tumors that develop at the expense of the ependymal coating. Their topography is in the cervicothoracic region [1] [2]. The most described extra-medullary forms are those located in the terminal filum or 
the medullary cone, often grade I of the WHO classification. This extra-medullary form of ependymoma accounts for almost $90 \%$ of intra-dural extra-medullary tumors with meningiomas, neuromas and neurofibromas [1] [2]. There is no pathognomonic clinical picture of these tumors that are revealed sometimes by discrete signs of myelopathy, which can evoke other medullary pathologies also; diagnostic input of MRI is of primary importance. The young adult between the fourth and fifth decade is the subject most often concerned [3] [4]. It is statistically well established that intra-medullary intra-spinal tumors are represented by ependymoma and astrocytoma, whereas in the extra-medullary position we find those developed at the expense of the nerve sheath and the meninge, namely schwannoma, and meningioma [3]. However, the literature reports rare cases of extramedullary intradural ependymoma excluding those located in the filum and the terminal cone (Table 1).

\section{Observation}

A 38-year-old female patient was admitted for a predominantly painful tetraparesthesia of the upper limbs with three months of history, associated with a left hemiparesis. He was also associated with episodes of vagal discomfort, asthenia, unencrypted hyperthermia, respiratory discomfort and relative impotence of the left-wing progressive build-up. The clinical examination found an asythenic, adynamic patient, a tetrapyramidal syndrome with a non-proportional left hemiparesis respecting the face, rated at three out of five (3/5) in the upper limb and two out of five (2/5) in the lower limb, as well as a Babinski sign on the left. The osteotendinous reflexes were lively. He had also been found on the examination a sensitive level thoracic T4 and discrete proprioceptive disorders left. MRI of the cervical spine showed extensive cervical extra-medullary intradural lesion of C3 to C5 with significant medullary edema (Figures 1 (a)-1(c)). A discretely hyperintense $\mathrm{T} 1$ lesion moderately enhances gadolinium. The treatment was posterior cervicotomy resection surgery, C3 to C5 laminectomy. In intradural exploration, a well-defined lesion, of firm consistency, lateralised on the left with a pre-medullary anterior extension which did not seem to infiltrate the marrow or engulf the nerve roots, had been discovered. Exeresis appeared macroscopically complete, but postoperative MRI showed a moderately compressive tumor residue (Figure 1(d)). A surgical reoperation by the same route initially was made four (4) weeks after the first surgery. It persisted a tumor residue on the MRI control. The postoperative course was marked by a complete recovery of traction and transient episodes of spasm of the left upper limb regressed under benzodiazepines. Histological examination of the lesion revealed a tumor proliferation of dense cellularity, with foci of necrosis, oval cells organized in large compact plates and pseudo-rosettes. The nucleo-cytoplasmic ratio was high. The nuclei appeared voluminous, irregular, and possessing a mottled chromatin. Mitosis Figures are visible on ten (10) out of fourteen (14) fields at forty (40) magnification as well as apoptotic bodies (Figure 2). Immunohistochemical analysis was performed on the operative part. The pathological cells expressed a high 
immunopositivity to the GFAP gliofibrillar acid protein and PS 100. EMA membrane epithelial antigen had shown focal labeling of tumor proliferation to cytoplasmic dot while proliferation index Ki-67 showed Heterogeneous labeling in the form of hot spot focus with $50 \%$ of labeled tumor cells. These pieces of information led to the conclusion of the diagnosis of grade III anaplastic ependymoma.

Table 1. Literature review of cases reported since 1951.

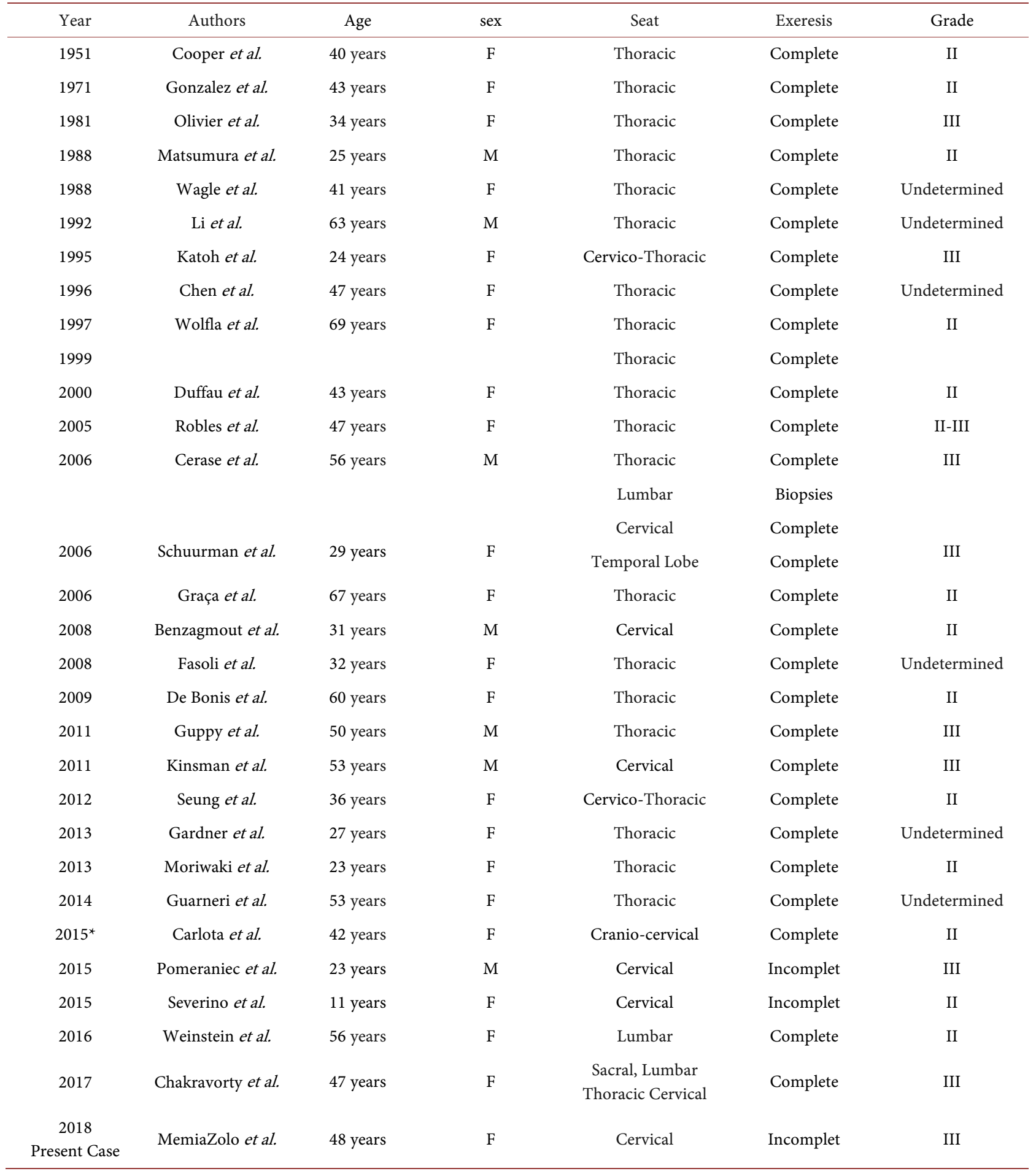




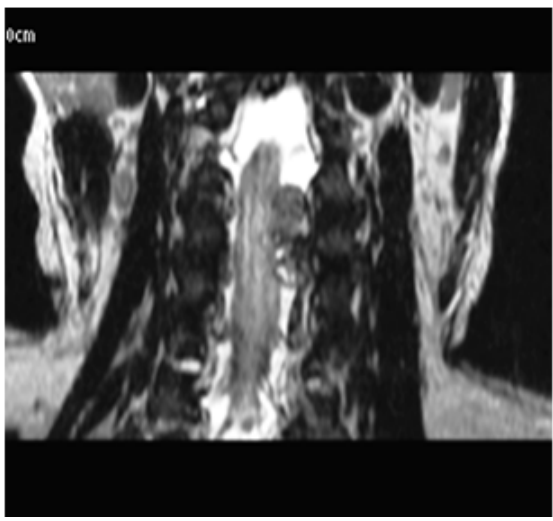

(a)

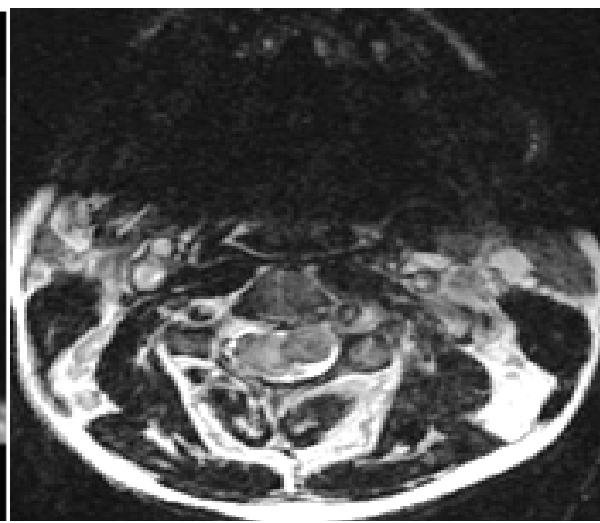

(b)

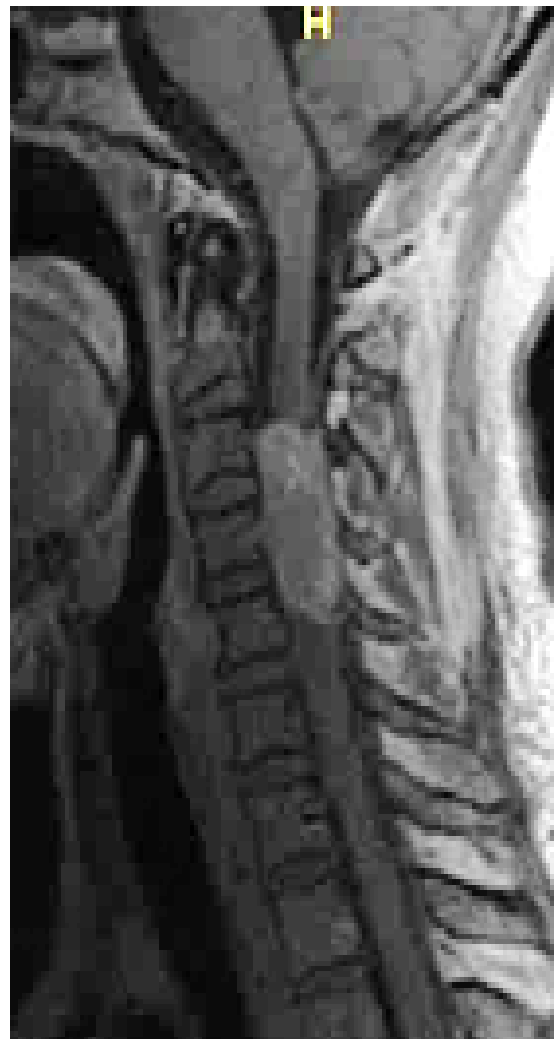

(c)

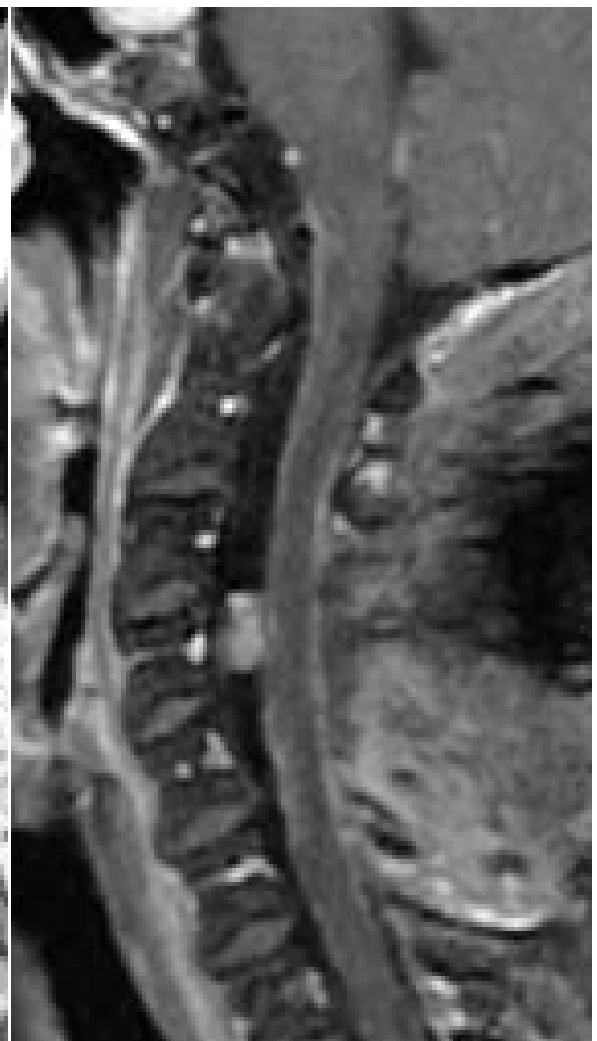

(d)

Figure 1. MRI. (a) Preoperative coronal cross-section T2; (b) Preoperative axial cross-section T2; (c) Preoperative T1 sagittal cross-section with gadolinium; (d) Postoperative MRI.

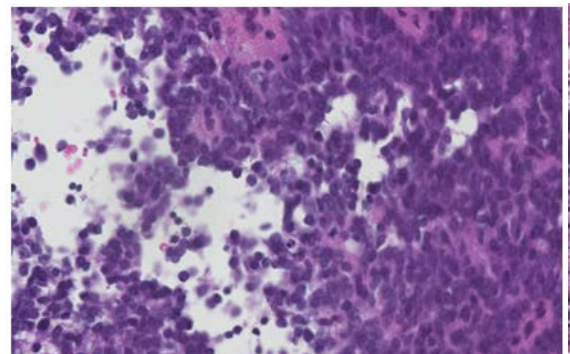

(a)

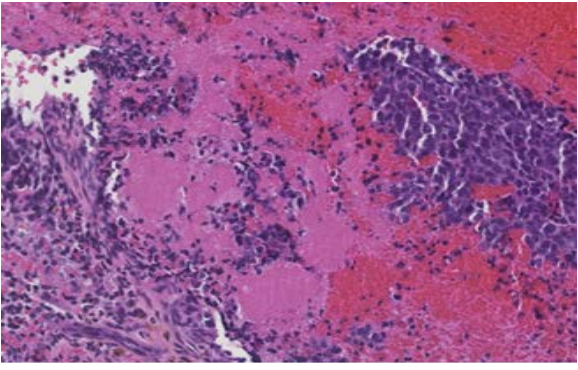

(b) 


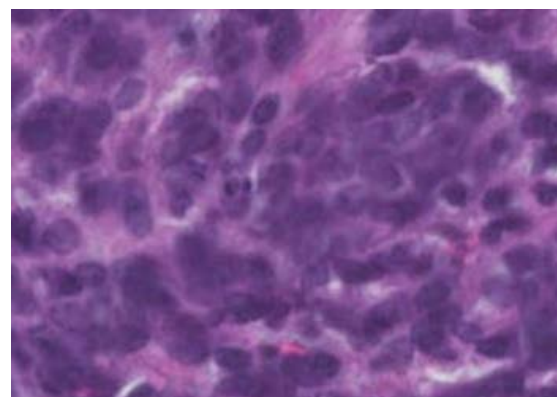

(c)

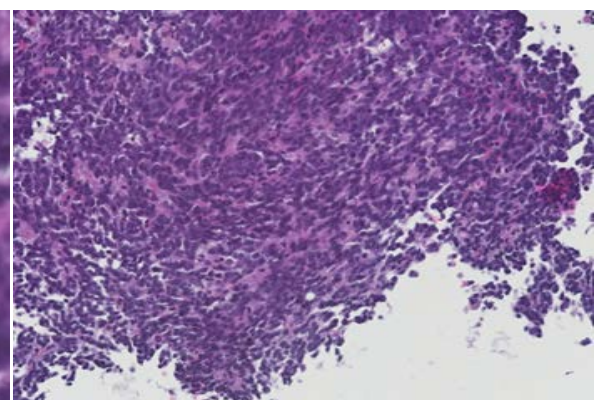

(d)

Figure 2. Histological cross-section Magnification of X40 images. Histological features of the ependymomas observed. Prerivascular pseudorosette were identified (H \& E, x200). The tumor exhibit slightly necrosis and High proliferative activity. (a) Pseudo rosette; (b) Necros; (c) Mitose; (d) Anaplasticependymoma.

A full brain and spinal MRI scan for other localizations was performed but was normal. A complementary treatment by adjuvant radiation therapy in tomotherapy by craniospinal irradiation at the dose of $36 \mathrm{~Gy}$ in fractions of $1.8 \mathrm{~Gy}$ with an overprint on the operated area, where persists a residue at the dose of 18 Gy in fraction of $1.8 \mathrm{~Gy}$.

\section{Discussion}

The diagnosis of extra-medullary intra-dural ependymoma is rare and is based on pathological examination [1] [2] [3]. In theory, it is expected that an ependymoma develops in contact with the ependymal coating and the pathogenesis of extramedullary ependymomas is controversial. The hypothesis of ectopic ependymal cells is the most commonly emitted but remains questionable insofar as these cells are born and develop in the center of the neural tube and do not migrate to the periphery. Cooper et al. suggested in 1951 that these ectopic cells would result from the exclusion of ependymal cells during neural tube closure [1] [4] [5]. Another hypothesis is that this ependymoma is in reality an exophytic ependymoma with a very reduced intramedullary development as already described [6] [7] [8]. The replay of MRI and the absence of medullary infiltration observed intraoperatively allow us to exclude this hypothesis in our patient. Based on the fact that neurogenesis persists in adults and that adult gliogenesis is no longer discussed, Johansson CB an animal model study, revealed the presence of pro-reproductive cells giving rise to olfactory neurons and astrocytes in various regions of the adult brain espendyma in the rat whereas ependyma has always been considered a simple epithelium [9].

It is established that the ependymocytes are linked together by zonulae adherens and gap junctions and not by tight junctions. This arrangement allows important exchanges between the ventricular cavity and the cerebral parenchyma. Knowing that the ependymocytes contain proteins conventionally expressed by parenchymal nervous cells whose intermediate filaments consist of vimentin present in the immature astrocytes, the nestin and the Notch 1 receptor which 
are two proteins which serve as markers of the neural and glial progenitors, they reveal an unexpected role in the ependyma, that of reserves of neural and glial progenitors [9]. This model could account for the hypothesis of ependymal cells that migrated into extra-medullary space and that would be by various mechanisms of activation at the origin of an ependymoma in this localization. An origin from germ cells is also evoked [10]. In 2006, surgical management in the same patient of an extra-medullary cervical and then lumbar tumor with in both cases a diagnosis of grade III anaplastic ependymoma followed twenty-four months later by the discovery of metastases extra cerebral parenchyma will lead Schuurmans to hypothesize a migration of tumor cells from the lumbar region to other sites [11]. The absence of another visible location on brain and medullary MRI makes it possible to exclude in our case the hypothesis of a metastasis. The WHO classification distinguishes three grades of ependymoma. Grade I includes myxopapillary ependymoma and sub-ependymoma. Grade II is ependymoma and Grade III is anaplastic ependymoma. He is the one who has the poorest prognosis with an increased risk of dissemination along the leptomeninges due to its ultra-structural features that differentiate him from others. [11] [12] [13]. It is not uncommon to find pathological ependymocytes at various stages or their association with astrocytoma within the same tumor contingent [14]. Of the twenty-eight (28) cases that we had, $25 \%$ were grade III extra-marrow ependymomas versus $51.8 \%$ grade II and $25 \%$ undetermined grade. This makes the extra-medullary ependymoma of grade III a very rare pathology. The female predominance [1] [11] [15] [16] observed was the origin of the hypothesis of a hormonal involvement in the pathogenesis of this tumor but this has never been conclusively demonstrated. To date, 8 cases have been described in men requiring reconsideration of the validity of the hormonal theory to explain the pathogenesis of ependymomas [17] [18] [19] [20] [21]. Among many other factors to be determined, female hormones could contribute to some extent to this pathogenesis. The nonspecific clinic is characterized by signs of thoracic or cervical spinal cord injury, which are more common in young adult female subjects, although one case has been reported in one child [22]. Often patients remain paucisymptomatic for a long time, which masks a slowly progressive evolution and explains a size often important at the time of the diagnosis. MRI is the baseline examination supporting the clinic to diagnose an extramedullary expansive process. It shows a well-defined lesion, isointense in T1, discretely hyperdense in T2 and which enhances moderately after Gadolinium injection [1] [15] [23]. These characteristics are similar to those of a meningioma or neuroma, but the absence of thickening of the dura mater, comet-shaped appearance or hourglass shape could have attracted attention to another hypothesis. Once the diagnosis of anaplastic ependymoma was made, it was completed by an exploration of the whole neuropath in search of other locations and this before any additional treatment. A reinterpretation of magnetic resonance imaging then sought unsuccessfully what could be an exophytic ependymoma with extra-medullary development leading us to describe an exclusively ex- 
tra-medullary ependymoma. According to the criteria of Mac Cormick, the patient went from a grade III preoperatively to a grade I postoperatively immediately. The good postoperative neurological recovery is in favor of extra-medullary lesion, which is confirmed by the MRI data, in particular the absence of enlargement of the cord.

The treatment of choice for this tumor is surgical excision, which must be complete when it is technically possible. All reported cases were treated surgically. In the vast majority of cases, the excision was complete. A hard, root or root bond or adhesion to the pia mater can be objectified intraoperatively [3] [13] [24], but this element is most often absent [1] [16] [21]. The importance of pre-medullary extension and possible Pia-Merienn adhesion may explain that our excision remained sub-total after two interventions despite a per-operative impression of complete excision. Among the references found, when additional treatment was necessary, it was radiotherapy. It was mostly used for Grade III ependymomas whether or not the excision was complete [2] [11] [21]. However, it has not been proposed to some patients who have had a complete excision of a grade III ependymoma. But the limits of the follow-up decline do not allow knowing if it was finally practiced or not. The trend, as for intramedullary tumors, is to complete the surgery with radiotherapy in case of anaplasia [13] [21] [25]-[33]. This would lead to better local control with improved survival [34] [35]. But this is not a consensus [36] [37]. We chose the option of cranio-spinal radiotherapy since excision was still incomplete despite two interventions increasing the risk of distant metastasis from an anaplastic tumor. Twelve (12) months after the first symptoms, neurological recovery is complete and professional activity has been resumed.

\section{Conclusion}

Intramoral intra duralantralplastic ependymoma is a rare diagnosis whose pathophysiology is still poorly understood. Its characteristics in magnetic resonance imaging bring it closer to the tumors usually encountered in this compartment and impose it as a differential diagnosis of meningioma and schwanoma. The treatment of choice consists of excision. Very few cases are currently collected in the literature which raises the problem of a lack of consensus for complementary treatment even if radiotherapy is widely used especially in case of anaplasia.

\section{Acknowledgements}

Prof. Vincent MOLINIE, MD, Department of Pathology, CHU Martinique; Ms. Djatougbe Yolande NYONHOE, of BOPTEL Togo communication department, for translation.

\section{Funding Information}

The authors declare that no funding was received. 


\section{Conflicts of Interest}

The authors declare no conflicts of interest regarding the publication of this paper.

\section{References}

[1] Duffau, H., Gazzaz, M., Kujas, M. and Fohano, D. (2000) Primary Intradural Extramedullary Ependymoma. Case Report and Review of Literature. Spine, 25, 1993-1995. https://doi.org/10.1097/00007632-200008010-00021

[2] Robles, S.G., Saldana, C., Boto, G.R., et al. (2005) Intradural Extramedullary Spinal Ependymoma. Bening Pathology? Spine, 30, E251-E254 https://doi.org/10.1097/01.brs.0000161008.13441.7b

[3] Kinsman, M.J., Callahan, J.D., Hattab, E.M. and Cohen-Gadol, A.A. (2011) Extramedullary Spinal Ependymoma: A Diagnostic Challenge and a Review of Literature. Clinical Neurology and Neurosurgery, 113, 661-664. https://doi.org/10.1016/j.clineuro.2011.02.021

[4] Cooper, I.S., Craig, W.M. and Kernohan, J.W. (1951) Tumors of the Spinal Cord; Primary Extramedullary Gliomas. Surgery Gynecology and Obstetrics, 92, 183-190.

[5] Pay, M., Yonekawa, Y. and Imhof, H.G. (1999) Solitary Thoracic Intradural Extramedullary Ependymoma. Journal of Clinical Neuroscience, 6, 344-345. https://doi.org/10.1016/S0967-5868(99)90061-9

[6] Chung, C.Y., Koffie, R.M., Dewitt, J.C. and Aronson, J.P. (2016) Thoracic Exophytic Ependymomas Masquerading as an Extra-Axial Bening Tumor. Journal of Clinical Neuroscience, 33, 221-225. https://doi.org/10.1016/j.jocn.2016.03.031

[7] Cicero, G., Giugno, A., Maugeri, R., Graziano, F., Basile, L. and Iacopino, D.G. (2015) A Rare Case of Extra-Intramedullary Dorsal Tanycitic Ependymoma Radicaly Removed with Intraoperative Neurophysiological Monitoring. Acta Medica Mediterranea, 31, 1229.

[8] Orozco, L.D. and Tiel, R.L. (2011) Exophytic Ependymoma of the Thoracic Spine. Journal of Clinical Neuroscience, 18, 1262-1264. https://doi.org/10.1016/j.jocn.2011.01.017

[9] Johansson, C.B., Monna, S., Clarke, D.L., Risling, M., Lendahl, U. and Frisen, J. (1999) Identification of a Neural, Stem Cells in the Adult Mammalian Central Nervous System. Cell, 96, 25-34. https://doi.org/10.1016/S0092-8674(00)80956-3

[10] Bell, D.A., Woodruff, J.M. and Scully, R.E. (1984) Ependymoma of the Broad Ligament. Report of Two Cases. The American Journal of Surgical Pathology, 8, 203-209. https://doi.org/10.1097/00000478-198403000-00006

[11] Schuurmans, M., Vanneste, A.L., Verstegen, M.J.T., et al. (2006) Spinal Extra-Medullary Anaplasic Ependymomas with Spinal and Intracranial Metastases. Journal of Neuro-Oncology, 79, 57-59. https://doi.org/10.1007/s11060-005-9114-9

[12] Alfara-Cervello, C., Soriano-Navarro, M., Ramirez, M., Bernet, L., Banaclocha, M.M. and Cano, R. (2015) Ultrastructural Pathology of Anaplastic and Grade II Ependymomas Reveals Distinctive Ciliary Structures: Electron Microscopy Redux. Ultrastructural Pathology, 39, 23-29. https://doi.org/10.3109/01913123.2014.906526

[13] Moriwaki, T. Iwatsuki, K., Ohnishi, Y., Umegaki, M., Ishihara, M. and Yoshimine, T. (2013) Intradural Extramedullary Spinal Ependymoma: A Case Report of Maligant Transformation Occurring. Asian Spine Journal, 7, 139-142.

https://doi.org/10.4184/asj.2013.7.2.139

[14] Weinstein, G.M., Arkun, K., Kryzanski, J., Lanfranchi, M., Gupta, G.K. and Bedi, H. 
(2016) Intradural Spinal Extramedullary Ependymoma with Astrocytoma Component. Case Report and Review of Literature. Case Report Pathology, 2016, Article ID 3534791. https://doi.org/10.1155/2016/3534791

[15] Bonis, P., Montano, N., Cioni, B., Colosimo, C., Lauriola, L., Papacci, F., et al. (2009) Primary Extramedullary Extradural Ependymoma of the Thoracic Spine Mimicking a Schwannoma. Journal of Neurology, Neurosurgery \& Psychiatry, 80, 579-581. https://doi.org/10.1136/jnnp.2008.151373

[16] Katoh, S., Ikata, T., Inoue, A., et al. (1995) Intradural Extramedullary Ependymomas. A Case Report. Spine, 20, 2036-2238. https://doi.org/10.1097/00007632-199509150-00017

[17] Boujraf, M.B.S., Oulali, N., Chbani, L., Amarti, A., Chakour, K. and El Faiz Chaoui, M. (2008) Intradural Extramedullary Ependymoma: Is There Constantly a Hormonal Relationship? Surgical Neurology, 70, 536-538. https://doi.org/10.1016/j.surneu.2007.05.055

[18] Matsumura, A., Hori, A. and Spoerri, O. (1988) Spinal Subependymoma Presenting as an Extramedullary Tumor: Case Report. Neurosurgery, 23, 115-117. https://doi.org/10.1097/00006123-198807000-00022

[19] Li, M.H., Holtas, S. and Larsson, E.M. (1992) MR Imaging of an Intradural Extramedullary Tumors. Acta Radiologica, 33, 207-212. https://doi.org/10.1177/028418519203300303

[20] Guppy, K.H., Hou, L., Moes, G.S. and Sahrakar, K. (2011) Spinal Intradural Extramedullary Anaplastic Ependymomas with Extradural Component. Case Report and Review of Literature. Surgical Neurology International, 2, 119. https://doi.org/10.4103/2152-7806.84246

[21] Cerase, A., Venturi, C., Olivieri, G., De Falco, D. and Miracco, C. (2006) Intradural Extramedullary Spinal Anaplasic Ependymoma. Case Illustration. Journal of Neurosurgery Spine, 5, 476. https://doi.org/10.3171/spi.2006.5.5.476

[22] Severino, M., Consales, A., Doglio, M., Tortora, D., Morana, G., Barra, S., Nozza, P. and Carrè, M.L. (2015) Intradural Extramedullary Ependymoma with Leptomeningeal Dissemination: The First Case Report in a Child and Literature Review. World Neurosurgery, 84, 865. https://doi.org/10.1016/j.wneu.2015.04.002

[23] Wagle, W.A., Jaufman, B. and Mincy, J.E. (1988) Intradural Extramedullary Ependymoma: Mr-Pathologic Correlation. Journal of Computer Assisted Tomography, 12, 705-707. https://doi.org/10.1097/00004728-198807000-00045

[24] Seung, M.H. and Dong, A.S. (2012) Intradural Extramedullary Ependymoma with Spinal Root Attachment: Case Report. Korean Journal of Spine, 9, 250-252. https://doi.org/10.14245/kjs.2012.9.3.250

[25] Lin, Y.-H., Huang, C., Wong, T.-T., Chen, M.-H., Shiau, C.-Y., Wang, L.-W., Ho, D.M.-T. and Yen, S.-H. (2005) Treatment of Spinal Cord Ependymomas by Surgery with or without Postoperative Radiotherapy. Journal of Neuro-Oncology, 71, 205-210. https://doi.org/10.1007/s11060-004-1386-y

[26] Gonzalez Feria, L., Fernandez Martin, F., Ginoves Sierra, M. and Galera Davidson, H. (1971) Giant Dorsal Extramedullary Ependymoma. Archivos de Neurobiologiá, 34, 325-332.

[27] Olivier, B., de Castro, A., Sarmiento, M.A., Arguello, C. and Blazquez, M.G. (1981) Dorsal Extramedullary Ependymoma. Archivos de Neurobiologiá, 44, 215-224.

[28] Cheng, C.H., Lee, T.C., Huang, H.Y. and Lui, C.C. (1996) Extramedullary Thoracic Myxopapillary Ependymoma. A Case Report of a Rare Tumor. Annals of the Academy 
of Medicine, Singapore, 25, 869-872.

[29] Wolfa, C.E., Azzarelli, B. and Shah, M.V. (1997) Primary Extramedullary Ependymoma of the Thoracic spine. Case Illustration. Journal of Neurosurgery, 87, 643. https://doi.org/10.3171/jns.1997.87.4.0643

[30] Graca, J., Gultasli, N., D’Heane, N., Brotchi, J., Salmon, I. and Baleriaux, D. (2006) Cystic Extramedullary Ependymoma. American Journal of Neuroradiology 27, 818-821.

[31] Fasoli, F., Minniti, G., Serio, N., Di Stefano, D., Romano, A., Ferrante, M., Fantozzi, L.M. and Bozao, A. (2008) Primary Intradural Extramedullary Ependymoma: Imaging Findings and Review of the Literature. A Case Report. The Neuroradiology Journal, 21, 239-243. https://doi.org/10.1177/197140090802100214

[32] Son, D.W., Song, G.S., Han, I.H. and Choi, B.K. (2011) Primary Extramedullary Ependymoma of the Cervical Spine: Case Report and Review of Literature. Journal of Korean Neurosurgical Society, 50, 57-59. https://doi.org/10.3340/jkns.2011.50.1.57

[33] Gardner, L., Kasliwal, M.K., Hempeck, N., Utset, M. and Gandhi, Y.N. (2013) Ependymoma: Unusual Differential for a Totally Extramedullary Intraspinal Tumor. Neurology India, 61, 687-690. https://doi.org/10.4103/0028-3886.125386

[34] Guarnieri, G., Tecame, M., Izzo, R., Zeccolini, F., Genovese, L. and Muto, M.(2014) Multisegmental Diffuse Intradural Extramedullary Ependymoma. An Extremely Rare Case. The Neuroradiology Journal, 27, 179-185. https://doi.org/10.15274/NRJ-2014-10018

[35] Lin, Y.H., Huang, C.I., Wong, T.T., et al. (2005) Treatment of Spinal Cord Ependymomas by Surgery with or without Post Operative Radiotherapy. Journal of Neuro-Oncology, 71, 205-210. https://doi.org/10.1007/s11060-004-1386-y

[36] Pomeraniec, I.J., Dallapiazza, R.F., Sumner, H.M., Lopes, M.B., Shaffrey, C.I. and Smith, J.S. (2015) Anaplastic Extramedullary Cervical Ependymoma with Leptomeningeal Metastasis. Journal of Clinical Neuroscience, 22, 1871-1876. https://doi.org/10.1016/j.jocn.2015.06.015

[37] Chakravorty, A., Frydenberg, E., Shein, T.T., Ly, J., Earls, P. and Steel, T. (2017) Multifocal Intradural Extramedullary Anaplasticependymoma of the Spine. Journal of Spine Surgery, 3, 727-731. https://doi.org/10.21037/jss.2017.11.10 